\title{
EDITORIAL
}

\section{Neuropathology and psychiatry}

More than 100 years have now been spent looking down the microscope at various parts of the nervous system. Progress at first was slow but with the improvement of techniques towards the end of the last century neuropathology came into its own and a wide range of abnormal conditions or processes were quickly identified and even at times explained. It seemed natural in those early days for psychiatrists, as well as pathologists, to take part in this pioneer work, and modern neuropathology derives in no small measure from asylum officers like Alzheimer and Nissl. In Great Britain there were Ferrier and, later, Bevan Lewis at Wakefield, Mott at Claybury and the Maudsley, and Ford Robertson in Edinburgh.

As the present century progressed, however, the early impetus slackened, and it began to look as if neuropathology would be left merely to contend with the diagnosis and classification of ever more obscure conditions. While the neuropathologists, not unlike psychiatrists, became immersed in their particular brand of disputation, the study of the nervous system would be carried forward by the biochemists, the physiologists, and all those in the younger branches of neuroscience. Neuropathologists tended at first to look on these enthusiastic new arrivals with a degree of scepticism, not least because they themselves had learned not long before how easily an advance can turn into an artefact. The hope was, however, that with time the pathologists would overcome this suspicion, and would transform their histological kitchens into biologically oriented laboratories in which the technical revolution could be more fully explored. Histochemical methods, freeze-drying of tissue, ultracentrifugation, tissue culture, phase contrast and interference microscopy, fluorescent and electron microscopy were some of the major advances any of which could be combined with the greatly improved and extended techniques for working on experimental animals and even on human tissue.

Fortunately this migration into modern neurobiology has largely taken place, and neuropathology, far from sinking into a decline, has not only expanded considerably in recent years but continues to do so. Whereas a generation ago the number of trained neuropathologists in Great Britain could be counted on one hand, there are now six or seven university chairs, some 40 to 50 senior academic or hospital medical staff, and many graduate research workers.

This expansion, however, has been overwhelmingly linked either to the basic sciences or, on the applied side, to neurology, to neurosurgery, and to general medicine. Psychiatry stands out as the exception and most psychiatrists today have little time either for the anatomy or the pathology of the nervous system. This lack of interest worries the neuropathologist. He knows only too well that his discipline, like others, has failed to throw appreciable light on the causation either of the major psychoses or of the neuroses. He feels, however, that because of this failure any more tangible contribution to other aspects of psychiatry has tended to be overlooked and this seems to him particularly unfortunate at a time when the field is opening up for the analysis of aberrant human behaviour in terms of abnormal cerebral structure, both at the statistical and at the molecular level.

The British Neuropathological Society was sufficiently concerned about the lack of this kind of work, as well as the need for it, to instigate in 1969 an inquiry into the views of the psychiatric world. With the help of the Royal Medico-Psychological Association, 171 psychiatric and subnormality hospitals were asked about their links with neuropathology. One hundred and twenty-seven hospitals replied, 40 of which were in the subnormality group. The total number of beds covered by the answers was about 140,000 . It emerged that $10 \%$ of this number of patients die each year in psychiatric hospitals (the figure is $2 \%$ for the subnormal population). In one out of six of these deaths a postmortem examination is carried out. This is usually made, often on the instruction of the coroner, to discover the immediate cause of death, and anything approaching a thorough study of the nervous 
system is rarely attempted. Indeed, it is doubtful whether one brain in 50 deaths in psychiatric hospitals is seen by a neuropathologist, let alone examined histologically. Moreover the size of even the tiny number that is so examined depends largely on the work being done in three or four small laboratories situated in mental or subnormality hospitals. In other words, senior neuropathologists employed in the psychiatric hospital service in England and Wales are thinly spread: there are two associated mainly with children and subnormality and one who works full-time in a psychiatric hospital. Departments of neuropathology in the universities and in some general hospitals give what help they can and this may be very good indeed. All too often, however, the staff is small, and may be otherwise occupied, and the clinical feedback tends to be negative or at least is too long delayed for interest to have been maintained. It is not surprising therefore that, with some exceptions, the general tenor of the hospital comments was critical, a little over half asserting that the services need to be improved. A few were content with manifestly inadequate or even nonexistent facilities.

Much the same picture of dissatisfaction, blurred by indifference, was found to exist with regard to teaching. Although some knowledge of the anatomy and the pathology of the nervous system is still expected in most examinations for a higher psychiatric qualification, few hospitals said that they could offer their staff in training any real help in these subjects, either within the group or even at times within the region. Some regretted this.

Does all this matter? Neuropathologists feel that it does but what solution have they to offer? How do they justify their continued existence, or the claim that their laboratories should be expanded? There are several answers. To start with, as already hinted, the neuropathologist would prefer to be seen less as a morbid anatomist consumed by the phenomena of death, and more as a biologist who illuminates nervous tissue, not as an end itself (which undoubtedly has its attractions) but in order to find out more about how it works and what happens to its owner in the presence of disease. Even the traditional ways of doing this are far from played out, particularly when they are combined with modern forms of clinical investigation and treatment. For example, the introduction of new electrophysiological and neurosurgical techniques has required the classical work on the pathology of epilepsy to be reappraised. As a result, the present interpretation of the role of the temporal lobe in the more complex forms of epileptic attack, often with psychological overtones, has altered fundamentally. Again, although the histopathological background of the commoner forms of dementia has been known for many years, it is constantly being expanded, and revised, often now with the help of the molecular biologists. On the applied side the combination of this knowledge with genetic, epidemiological, and statistical studies of cerebral degenerative processes has scarcely been attempted. Knowledge of the effects of hypoxia, of malnutrition, and of metabolic disorders on the intelligence, on the behaviour, and on the brain of the child and even of the foetus is now increasing rapidly. All these are, or should be, the concern of the neuropathologist.

Encephalitis lethargica, for example, has almost died away but other subacute forms of encephalitis in children, with their devastating psychological as well as pathological effects, have become more prominent. Only now though, after 25 years study by pathologists and virologists, has the evidence been found which attributes them to past infection with the measles virus. Again, there is little evidence before the 1940s that the human temporal lobes were specially vulnerable to the herpes simplex virus and even to other agents. As in all forms of bilateral damage in the depths of the temporal lobe, such illnesses, when they last for months or years, are grossly disturbing to the mind and memory rather than to the body. The different ways in which the brain may be damaged by head injury, together with the physical basis for the 'instant dementia' that may result from the shearing of nerve fibres, is a further field in which important advances continue to be made. Another series of neurohistological observations has uncovered the curiously selective way in which certain parts of the brain may react when malignant disease is present remote from the nervous system. This is all the more interesting not only because the reaction itself often resembles that seen in viral infections but also because its limbic localization seems to lie at the root of some of the mental changes occasionally found in patients with cancer. An even more intriguing problem has gradually unfolded with the discovery of kuru-a disease which is apparently confined to certain tribes in the highlands of New 
Guinea. At first an abstruse clinicopathological observation on an excessively rare form of hereditary cerebral degeneration, its continued investigation has led not only to its passage to animals but also to the discovery that the totally obscure forms of presenile dementia, subsumed under the title of Creutzfeld-Jacob disease, can also be transmitted. This unexpected development has not only helped to resurrect Greenfield's hypothesis of the 'slow virus' lying dormant in the nervous system; it may well have opened up a new way to investigate the aetiology of cerebral degeneration.

Most of this kind of work, however, is done in a piecemeal way and few concerted or systematic attempts are made in Great Britain to link the study of the abnormal brain with the vagaries of human thought and behaviour. Basic research on the nervous tissue of small animals may be tolerably well supported; the study of the primate and, above all, the human brain is not, even though the closer research comes to tackling the problems of man as man the more need there is to examine the human rather than any other nervous system. This is far less impracticable on a long-term basis than is generally imagined and it is a half-truth to assert that such work cannot be both humane and done to standards at least approaching those of the experimental worker. The neuropathologist has the key position here, for more than anyone else he stands on the bridge linking the clinical research workers with those neurobiologists who are interested in the chemical or microscopical study of the normal and abnormal human nervous system. Even acting as little more than a middle man, he can provide tissue for the chemists within an hour of death. Working with neurosurgeons, he is at the source of much material that cries out for expert neuroanatomical study and the same applies to collaboration with experimental psychologists and physiologists. In his own field electron microscopy has greatly increased the range of study possible to him, while it now looks as if the accurate assessment of cell and particle populations in nervous tissue using an image analyser will soon be practicable.

Work of this kind is best done in a hospital or at least in a clinical setting in which service, teaching, and research can all be usefully combined. Any major development along these lines, however, whereever it is situated, cannot take place without joint action by the National Health Service, the universities, and the Medical Research Council. There is now a real need for these authorities to get together and to go beyond their splintered short-term support of miniature groups or even of individuals scattered around the country. The neuropathological study of man, like so much work on the nervous system, is slow and complex and it takes a long time to get going. It would be wrong in this context, for example, not to take issue with the assurance of the Medical Research Council that a project has failed if it has not been completed within three years. In psychiatric neuropathology it often takes longer than that to organize the material, and finding younger colleagues to join in the work may be still more of a job.

Indeed, this is often the most difficult thing of all, for the chances of making a medical career in the subject can seldom have been worse. Psychiatrists are busy founding one Royal College; pathologists have just put up another. Unfortunately, there is no communicating door between the two, and nowadays the only novice with any prospects has to be someone so drawn to the investigation of the nervous system and human behaviour that he is prepared to spend the best part of five years doing something else. After that time, he will have undergone the training mandatory for all pathologists and he may have obtained their higher qualification. In the absence of any psychiatric link, however, he may well have forgotten why he started.

J. A. N. CORSELLIS 